\title{
Research and Design of Household Load Interaction Control Devices
}

\author{
Zhao Zhiwen \\ STATE GRID (SHAGNHAI) SMART POWER GRIDS \\ R\&D INVESTMENT CO.LTD \\ Shanghai, China
}

Chen Songsong

China Electric Power Research Institute

Beijing, China

chensongsong2010@163.com

Zhao Jianyi

\section{STATE GRID (SHAGNHAI) SMART POWER GRIDS R\&D INVESTMENT CO.LTD \\ Shanghai, China}

\begin{abstract}
A interface equipment's design and application
\end{abstract} method is put forward, which can be used to guide related equipment vendors to complete the production and transformation of home appliances of power demand response and improve the enthusiasm of the residents participation in demand response.This paper introduce the hardware and software architecture for a interactive control device of residential load, complete the design of the changes process, software and hardware and design the The application method of the device on demand response scenarios(for example, direct load control,interruptible load control and automated demand response). Without increasing the cost of existing home appliances, the device can expand the demand response function of household appliances so that the two-way interaction of residential users and power network enterprise.

KeyWords-interface; interaction; demand response; household user; home appliance

\author{
He Ziheng \\ North China Electric Power University \\ Beijing, China \\ 413501559@qq.com \\ Song Xuming \\ STATE GRID (SHAGNHAI) SMART POWER GRIDS \\ R\&D INVESTMENT CO.LTD \\ Shanghai, China
}

\section{INTRODUCTION}

As the main character and the construction object of smart grids, "intelligent interaction"refers to the two-way interaction between information and electric energy. This information interaction includes encouraging users to change the traditional way of electricity consumption , to actively participate in power grid operation and to adjust power mode based on the spot price; this electric energy interaction includes grid-connected modes of "plug and play" distributed power ${ }^{[1-3]}$. The electricity information acquisition and intelligent interactive control aiming at residential electrical equipment is an important demand side management techniques, which is also an important way to realize the "intelligent interaction"[4-6]. With the present development of expertise on smart meters, communication message and load control, the existing intelligent sockets pointing at electric appliances can realize the electric energy metering and the on-off control ,but these sockets don't possess strong information alternation function and can't adjust the running state of the electric equipment according control requirements of power grid enterprises ${ }^{[7-8]}$. 
For resolving this problem, Application of a interactive control device for the residential load of grain is designed as the interactive terminal equipment of the residential electrical equipment and enterprise. This device on the user side connecting the extended interfaces provided by the electrical equipment at work can receive the information from the grid enterprise related application system ( e.g. Automatic demand response system), collect the data of the equipments and control the running state of the equipments ${ }^{[9]}$.

\section{HARDWARE DESIGN}

\section{A. Hardware structure and function design}

Hardware of system of interactive control device for the residential load includes microprocessor module, communication module, security module, measurement module, A/D conversion module, voltage transformer, interface etc. The functions of each module are as follows.

- The microprocessor module is the run control module designed for the interaction control device of the residential load;

- The communication module is used in supporting the wireless communication between the interaction control device of the residential load and residential interior gateway .

- The security module has two functions, secure authentication and communication encryption, secure authentication is used to verify the legality of residential electrical equipments; and communication encryption is used to participate in the world dialogue about anthropology in disciplinary sense.

- The measurement module calculates the actual electricity data of household appliances using the digital signals output by A/D conversion module.

- The A/D conversion module converts the the secondary voltages output by the voltage transformer and the analog current signals input from interface current terminal into digital signals.

- The voltage transformer turn voltage of $220 \mathrm{~V}$ or $380 \mathrm{~V}$ into the weakly voltage received by the A/D conversion module, which satisfies the measurement needs of the voltage and current quantity of interactive control device for resident load.

- The interaction interface is a pluggable joint, and forms the hermaphrodite connector with extension points provided by electrical equipments of user. This interface includes power supply terminal, voltage terminal, current terminal and communication terminal. Power terminal is used to power interactive control device of residential load; voltage terminal directly introduce power wires of the residential devices into voltage transformer; current terminal is used to connect the output ports of internal current transformer for residential devices; communication terminal connect the microprocessor module for interactive control device of residential load with the internal controller for residential devices ,so information exchange between the interactive control device of residential load and devices can be achieved.

The hardware structure of the resident load interactive control device is shown in Figure 1.

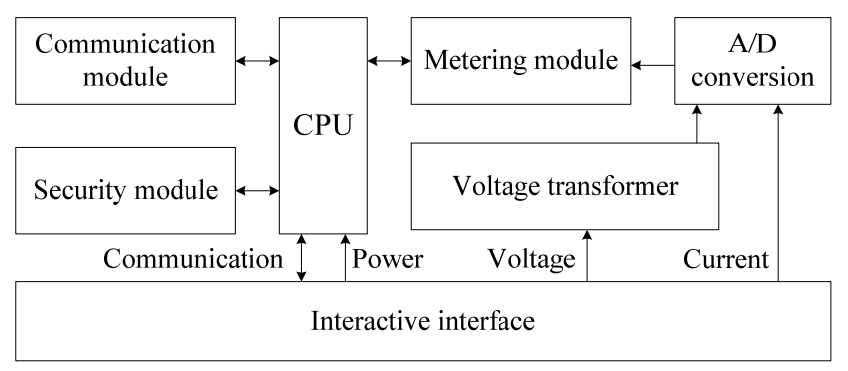

Fig.1. Structure sketch map of resident load interactive control device

\section{B. Structure design of interactive interface}

The interactive interface which is a interface that enable plug-pull form a pair of the male female interface. The interactive interface includes power supply terminal, voltage terminal, current terminal and communication terminal. The functions of each part are as follows:

- The power supply terminals, including the $+5 \mathrm{~V}$ voltage terminal and the ground terminal, draw power directly from the internal electrical equipment through the terminals of the corresponding device's extended interface, which can power the interactive control device of residential load. 
- The voltage terminals, including the positive voltage terminal and the negative voltage terminal, can introduce $220 \mathrm{v}$ or $380 \mathrm{~V}$ voltage signal from power leads through the terminals of the corresponding device's extended interface.

- The current terminals, including the positive current terminal and the negative current terminal, can introduce the current signals output by the current transformer conversion device's through the terminals of the corresponding device’s extended interface.

- The communication terminal , including the Rx terminal and Tx terminal, can connect with the controller in the device through the terminals of the corresponding device's extended interface, which support the information exchange between the interactive control device of residential load and the electric equipment.

The interactive interface structure of the residential load interactive control device is shown in Figure 2.

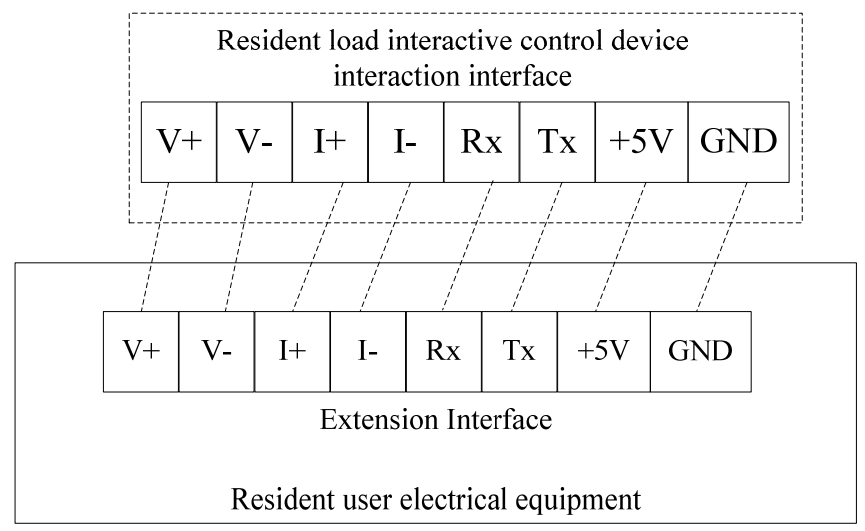

Fig.2.The sketch of the interactive interface of the residential load interactive control device

\section{SOFTWARE DESIGN}

\section{A. Software Framework Design}

The software system of the residential load interactive control device adopted modular design which includes the main control program module, the electric energy metering module, the wireless driving module, the safe encryption module, the electrical equipment control module, the interactive interface module, the data storage module and so on. The structure as shown in Figure 3.

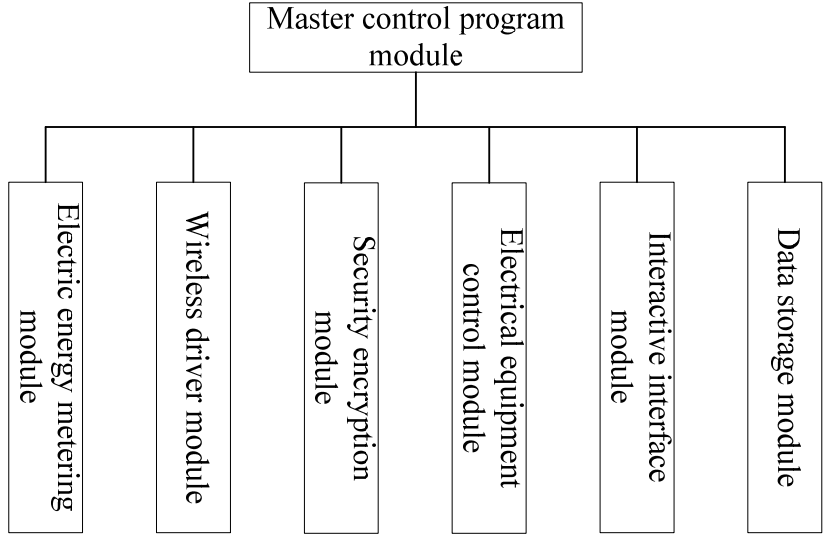

Fig. 3. The sketch map of software system of resident load interactive control device

The functions of each software module are as follows:

- As a key module, the main control program module is responsible for the coordination of the other modules, and this module control the execution sequence of each modules by judging the system identification and the operation state of each module program.

- The electric energy metering module is used to measure electric metering data of the appliances, and the data includes voltage, current, power, active power, reactive power ,power factor and so on.

- The wireless driver module is used to complete these fuctions which include the initialization of communication module, the reading-writing of communication bus, the reading-writing of register, settings the transmission and the receiving mode of data packet, and so on.

- The safe encryption module accepts the request for master control program module,carries out the security authentication , implements data encryption and decryption

- The electrical equipment control module turn the control command from the local and remote business system into the control signal which is suitable for electrical equipment identification.

- The interactive interface module control the operation of the interactive interface. 
- The data storage module stores the relevant calculations depending on the requirement of the main control program.

\section{B. Software running process}

When the interactive control device of the residential load is powered on, The system initialization is carried out by the master control program module. Initialized which include: Hardware interface, system registers, timers, system identification parameters, etc. After system initialized, the main control loop is entered. Depending the local or remote system communication message, the control device performs related operations and performs the interrupt operations based on self-generated related interrupt marker such as overload flag, event flag, timing mark . The specific software workflow is shown in Figure 4.

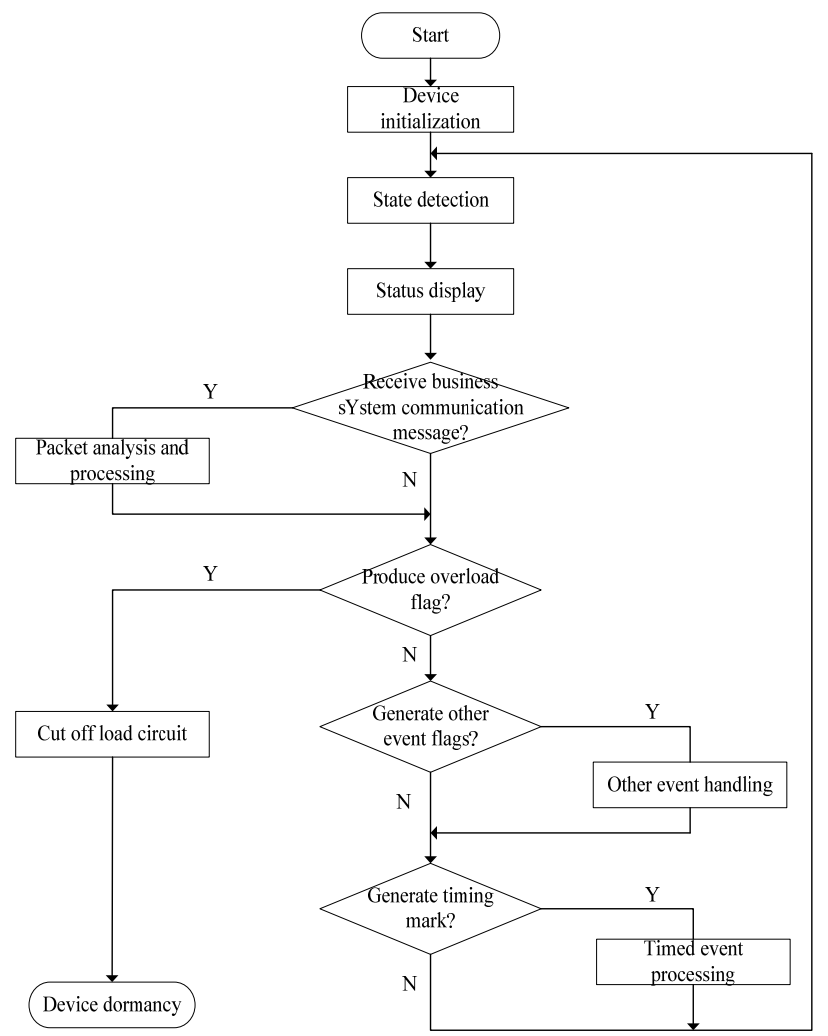

Fig. 4. The software flowchart of resident load interactive control device

\section{APPLICATION AND BENEFITS}

\section{A. Application methods and application scenarios}

The resident load interactive control device works though the extended interface provided by an interactive interface inserting the home appliance. The device with the hot-swappable function, so the residents can pull out the device directly When do not want to participate in the interaction with power network.

The resident load interactive control device connecting with home gateway through wireless mode Supports the Communication Methods including WSN,WiFi and so on. This device has two business types,namely the local business and the remote service.

The local business means that the resident load interactive control device joins the local communication network for residents through communication module connected to user communication gateway. Via the client software of the terminal equipments such as telephone and laptop ,the resident can view the energy consumption of the corresponding electrical equipments, calculate energy efficiency data of electric equipments and control the work state of electrical equipments.

The remote service means that the resident load interactive control device joins the public internet and other remote communication networks through communication module connected to user communication gateway. By the business operating system, the business operation department (e.g. the power grid enterprise and third party energy saving service mechanism) can realize communication interaction with the resident load interactive control device, operate the automatic demand response, manage energy efficiency and so on.

Its application method is shown in figure 5. 


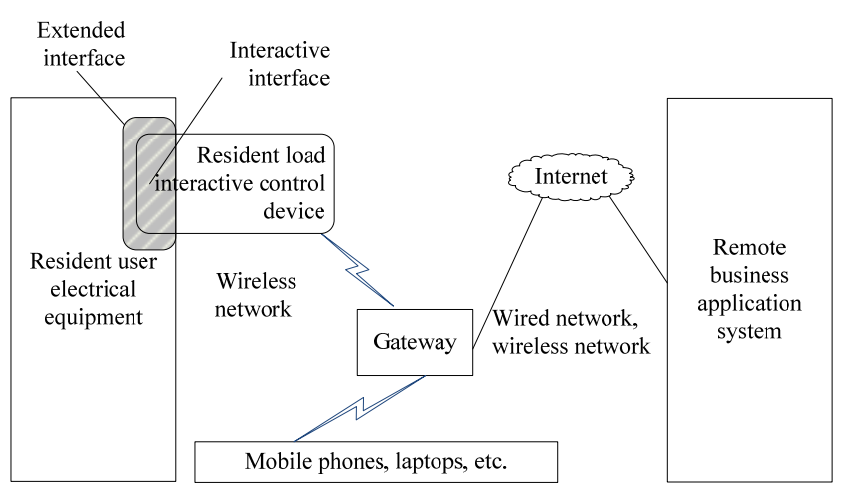

Fig. 5. Diagram of the application method of the resident load interactive control device

The application method of the resident load interactive control device, Specifically, including the following steps:

- By pluggable connector inserted into the extended interface of electrical equipment, the resident load interactive control device can work and support hot-pluggable operation mode.

- By the built-in 5V DC power supply of appliances, the resident load interactive control device is powered by itself and communicate with the appliances via the communication terminal.

- The resident load interactive control device via the communication module realize communication interaction with the local network system and the remote network system.

- By using the client software of the terminal equipments such as telephone and laptop, the resident can Control the operation of electrical equipment in local network.

- The operation department responsible for demand response business can control the electrical equipments via the remote network, which realizes the automatic demand response function of the Residential electrical equipments.

The resident load interactive control device can be used to support the intelligent community system, intelligent home system, automatic demand response system and so on for Manage and control of devices. Application scenarios are shown in figure 6.

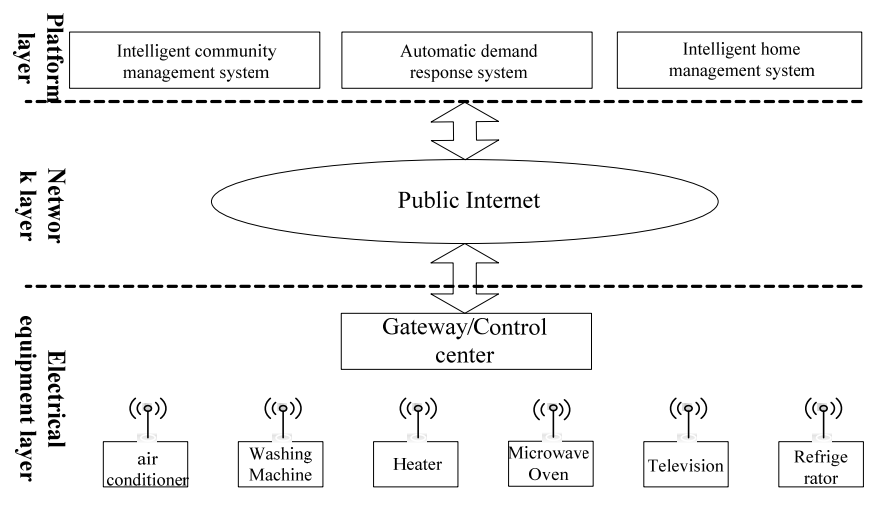

Fig. 6 application scenarios of the resident load interactive control device

\section{B. Benefits of application}

As a user-side terminal device for demand response, the Application benefit of the resident load interactive control device mainly lies in two aspects: demand response and energy management. The automatic demand responsebusiness application and the energy efficiency management of third party energy saving service can be come true by the collection of energy efficiency data and the control for the appliances.

- In the respect of Automatic demand response service, the resident load interactive control device acts as a demand response terminal controller of residential electrical equipments.The device control the equipment according to the corresponding demand response command .

- In the respect of energy efficiency management, the resident load interactive control device via the collection of energy efficiency data can analyse energy consumption of electrical equipment, roughly estimate the energy efficiency of electrical equipment and comparatively analyse the energy efficiency among the same type. The above data and analysis results can be not only used to provide the energy saving recommendations and the energy saving management methods, they are also used to expand energy-saving service business for the third party energy saving service and provide the credible data for the marketing strategy of energy-efficient appliances. 


\section{CONCLUSION}

In the respect of hardware design, software design, application scenarios, this paper provides a interface control device to support the residential appliances realize the electric power demand response. Residential load interaction control device can complete the information exchange between home appliances and power system, build up foundation for the implementation of demand response.In order to better meet the follow-up demand response system, the performs of this device (e.g. Scalability, security, interoperability and compatibility) should be further studied . Aim at the power grid construction of different nation, the device should be further optimized for the promotion of demand response service .

\section{REFERENCES}

[1] Gao Ciwei, Liang Tiantian, Li Huixing, Zhai Haibao. Development and Application of Open Automated Demand Response[J]. Power System Technology, 2013, 27(3): 692-698.

[2] Sheng Wanxing, Shi Changkai, Sun Junping, Zhang Bo, Zhang Tianshu. Characteristics and Research Framework of Automated Demand Response in Smart Utilization[J]. Automation of Electric Power Systems, 2013,37(23):1-7.

[3] OpenADR Alliance. OpenADR 2.0 Profile spencification A profile, revision No.1.0[S], 2012-10-10. http://www.openadr.org.

[4] Zhao Hongtu, Zhu Zhizhong, Yu Erkeng. Study on Demand Response Markets and Programs in Electricity Markets[J]. Power System Technology, 2010,34(5):146-153.

[5] Miao Xin, Zhang Kai, Tian Shiming, Li Jianqi, Yin Shugang, Zhao Ziyan. Information Communication System Supporting Smart Grid[J] Power System Technology, 2009,33(17):8-13.

[6] Li Yang, Wang Beibei, Song Hongkun. Demand side response and its application[J], POWER DSM, 2005, 6(5): 13-18.

[7] Yu Rongshan, Yang Wenxian, Rahardja S. A statistical demand-price model with its application in optimal real-time price[J].IEEE Transactions on Smart Grid, 2012, 3(4): 1734-1742.

[8] Ji H Y, Baldick R, Novoselac A, Dynamic demand response controller based on real-time retail price for residential buildings[J].IEEE Transactions on Smart Grid 2013 , 5(1):121-129.

[9] International Electro technical Commission IEC PC118. Smart grid user interface technical report v0.9 [S]. Geneva: IEC, 2013. 